\title{
Efficacy of Surgical Transversus Abdominis Plane Block in Patients Undergoing Cesarean Delivery
}

\author{
Penumuchu Sravani ${ }^{1}$, Chaitanya Indrani ${ }^{2}$, Sira P Rajanna ${ }^{3}$, Rajiv K Saxena ${ }^{4}$
}

\begin{abstract}
Background: The surgical transversus abdominis plane (TAP) block is an established technique for postoperative analgesia following abdominal surgery. However, it has not been practiced frequently by obstetricians. This work was done to study the efficacy of the surgical TAP block after cesarean delivery (CD).

Materials and methods: The study included 100 women undergoing CD in MVJ Medical College and Research Hospital, Hoskote, Bengaluru, Karnataka. The operating obstetrician performed a surgical TAP block for 50 participants in the "Study" group. Twenty milliliters of $0.25 \%$ bupivacaine was injected in the transversus abdominis neurofascial plane, on either side. Another 50 participants were included in the "Control" group. Postoperatively, visual analog scores (VAS) for pain were monitored for 24 hours. Whenever the patient demanded rescue analgesia or VAS was recorded as 4 or more, rescue analgesia was administered with intravenous injection tramadol $50 \mathrm{mg}$. The time of the first rescue analgesia and the total dose of rescue analgesics required in the first 24 hours were recorded. The patients in the "Control" group routinely received intravenous injection tramadol $50 \mathrm{mg}$, 8th hourly for pain relief.

Results: The difference in the mean VAS score at all time intervals between the two groups was statistically significant $(p<0.05)$. The mean time to first rescue analgesia in the "Study" group and "Control" group was $11.7 \pm 7.344$ and $2.1 \pm 1.125$ hours, respectively, and the total tramadol consumption was $50 \pm 28.571$ and $180 \pm 26.726 \mathrm{mg}$, respectively. This difference was statistically highly significant $(p<0.001)$.

Conclusion: Surgical TAP block is an important adjunct in the multimodal pain management strategy and should be practiced more often in obstetric practice.

Keywords: Cesarean delivery, Postoperative analgesia, Postoperative pain, Surgical transversus abdominis plane block, Tramadol.

Journal of South Asian Federation of Obstetrics and Gynaecology (2020): 10.5005/jp-journals-10006-1828
\end{abstract}

\section{INTRODUCTION}

The modern obstetric practice has made cesarean delivery $(C D)$ safe and easily accessible. Opioid derivatives have long been used to provide effective postoperative analgesia, but they are notorious for producing side effects like nausea and vomiting, and occasionally respiratory depression. These side effects can be reduced or eliminated by employing an alternate simple, reliable, and effective regional anesthetic technique like the transversus abdominis plane (TAP) block.

An important component of pain, experienced by the patients after abdominal surgery, is from the abdominal wall incision. The cutaneous nerves supplying the anterior abdominal wall (T6 to L1) pass in the neurofascial plane between the internal oblique muscle and the transversus abdominis muscle (Fig. 1), ${ }^{1,2}$ These cutaneous nerves can be blocked by injecting an anesthetic into this plane. ${ }^{3,4}$ Transversus abdominis plane block has become an established modality of providing postoperative analgesia with added benefits of improved analgesia and decreased opioid consumption. ${ }^{5-8}$ Rafi first described the TAP block in 2001, since then it has been practiced by the anesthesiologists as a blind technique based on body landmarks to identify "triangle of Petit". ${ }^{3}$ With the advent of ultrasound, this technique has become safer when it is performed under ultrasound guidance. In 2010, Owen et al. described their novel surgical TAP block technique, in patients undergoing $C D$. Herein, the surgeon gives the TAP block under direct vision before closing the abdomen. ${ }^{9}$ However, this technique has not been practiced frequently by obstetricians. This work was done to study the efficacy of the surgical TAP block after CD. We also looked at the ease of performance of the
${ }^{1-4}$ Department of Obstetrics and Gynaecology, MVJ Medical College and Research Hospital, Bengaluru, Karnataka, India

Corresponding Author: Rajiv K Saxena, Department of Obstetrics and Gynaecology, MVJ Medical College and Research Hospital, Bengaluru, Karnataka, India, Phone: +918660409840, e-mail: drrajivsaxena@ yahoo.com

How to cite this article: Sravani P, Indrani C, Rajanna SP, et al. Efficacy of Surgical Transversus Abdominis Plane Block in Patients Undergoing Cesarean Delivery. J South Asian Feder Obst Gynae 2020;12(5): 302-306.

Source of support: Nil

Conflict of interest: None

surgical TAP block and the overall patient satisfaction score with the postoperative analgesia provided.

\section{Materials and Methods}

This was a hospital-based prospective comparative study, conducted over a period of 2 years starting in November 2017. The study included 100 pregnant women posted for elective/ emergency CD in MVJ Medical College and Research Hospital, Hoskote, Bengaluru, Karnataka. The operating obstetrician performed a surgical TAP block on 50 participants in the "Study" group. Another 50 participants were included in the "Control" group, using a "convenience" sampling method.

Surgical TAP block was given after closing the uterus and establishing hemostasis. The anterior abdominal wall was elevated for a clear view (Fig. 2). The surgeon used his left hand to palpate the 


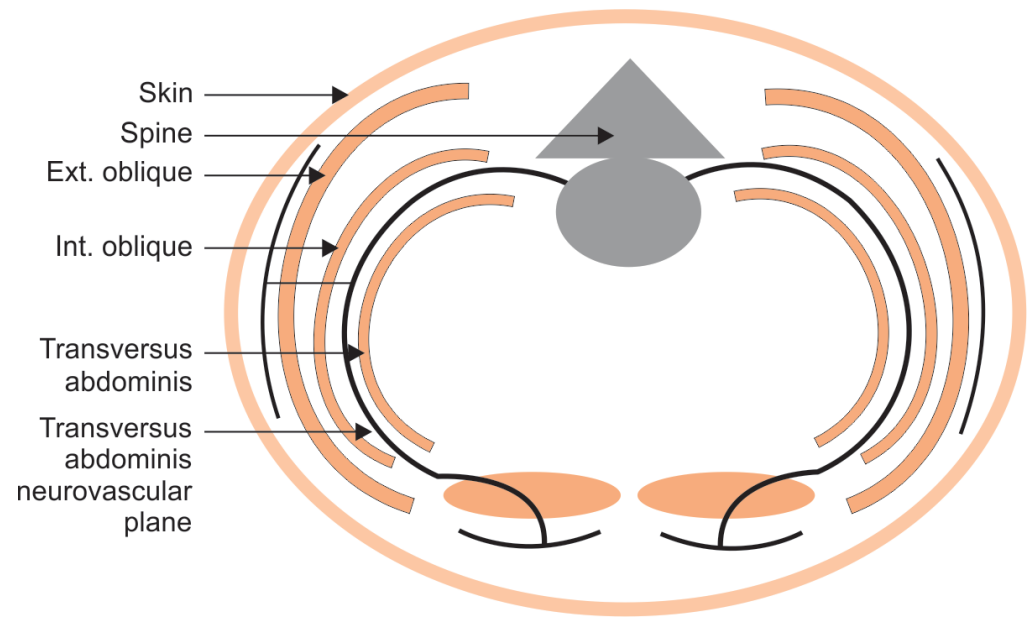

Fig. 1: Schematic diagram of transverse section of the abdominal wall

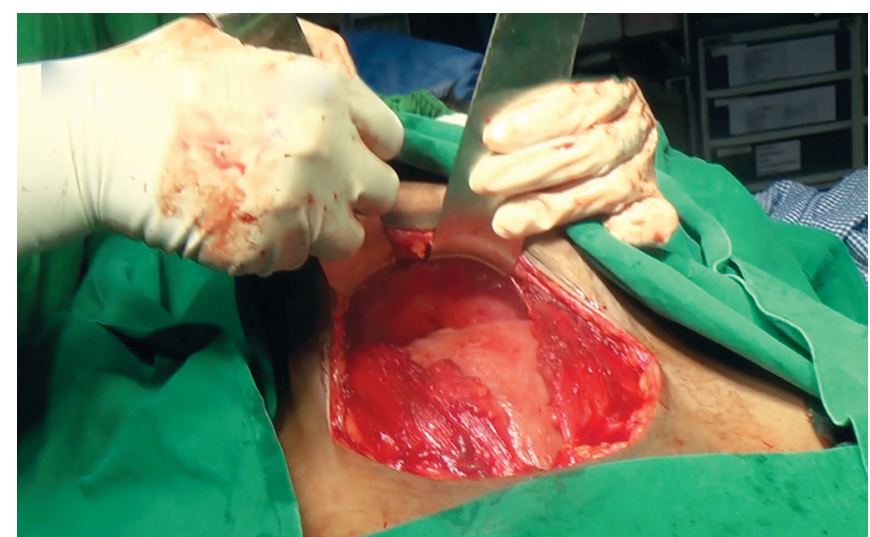

Fig. 2: Anterior abdominal wall retracted

lateral border of the rectus muscle at the level of the umbilicus, from the peritoneal surface, this point of entry ensured that the injury to the inferior epigastric vessels was avoided (Fig. 3). The surgeon held the syringe with $20 \mathrm{~mL}$ of $0.25 \%$ bupivacaine, and a blunt-tip needle $(18 \mathrm{G})$ in the right hand. Using the left hand to guide the blunt tip needle, pierced the parietal peritoneum at the point of entry, then it was gently advanced until it pierced the transversus abdominis fascia, which was felt as a loss of resistance ("one pop") (Fig. 4). Gentle aspiration was done to ensure that the tip of the needle is not in a blood vessel, thereafter, $20 \mathrm{~mL}$ of $0.25 \%$ ( $2.5 \mathrm{mg} /$ $\mathrm{mL}$ ) bupivacaine was introduced slowly in the TAP, with very little resistance. As with the conventional method, the anesthesiologist monitored the patient closely for any signs of toxicity. The surgeon then moved to the opposite side of the operating table and performed the surgical TAP block on the contralateral side. This dose of bupivacaine was equivalent to anhydrous bupivacaine hydrochloride $50 \mathrm{mg}$ on either side. The surgeon maintained a clear vision of the site of injection throughout, thereby ensuring that there was no inadvertent damage to any viscera. After the procedure, the rectus sheath and skin were closed. Postoperatively, all patients received diclofenac suppository before shifting to the ward.

All patients were monitored in the postoperative period, at 60 minutes, 2 hours, 4 hours, 6 hours, 12 hours, and 24 hours for pain, using visual analog scores (VAS). In the study group, whenever a

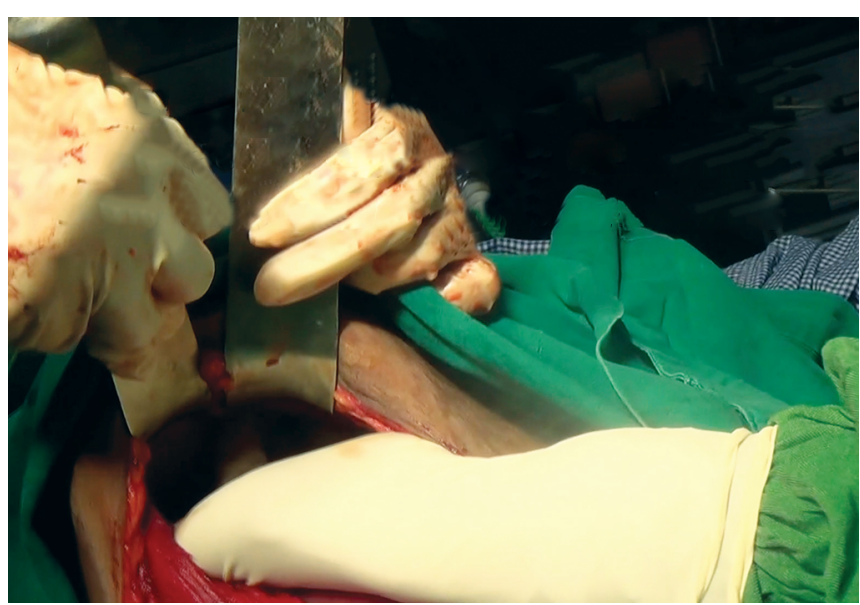

Fig. 3: Palpating lateral border of rectus muscle

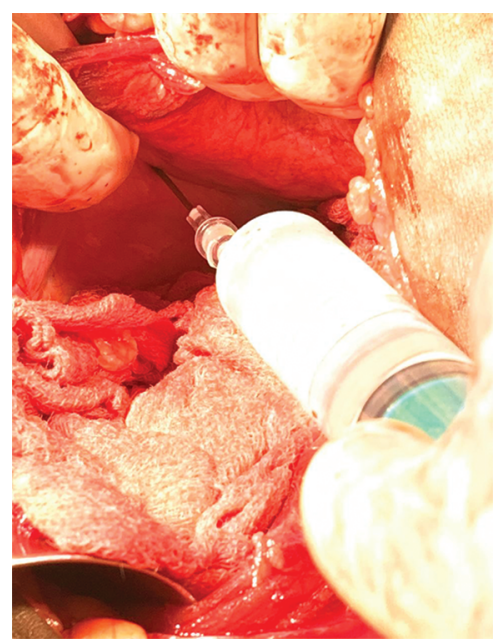

Fig. 4: Injecting bupivacaine under vision

patient requested for analgesia, or VAS was recorded as 4 or more, rescue analgesia was administered with intravenous inj. tramadol 50 $\mathrm{mg}$. The patients in the control group routinely received intravenous inj. tramadol $50 \mathrm{mg}$, 8th hourly for pain relief. The time of request for the first rescue analgesia was recorded for all patients. The total 
dose of rescue analgesics required in the first 24 hours was also recorded. The occurrence of any complications was noted. After the first 24 hours of $C D$, patient satisfaction with the postoperative pain relief was recorded, on a scale of 0 to 10, with 0 indicating "not satisfied at all" and 10 indicating "fully satisfied" with postoperative pain management. Details of the obstetrician performing the surgical TAP block in the study group were also recorded.

\section{Results}

One hundred patients undergoing CD were allocated to two groups, the "Study" group or the "Control" group, using "convenience" sampling. Both groups were comparable in terms of their age, height, and weight (Table 1).

\section{Postoperative Pain}

The difference in mean VAS at defined time intervals, i.e., at 60 minutes, 2 hours, 4 hours, 6 hours, 12 hours, and 24 hours, between the two groups, was statistically significant (Table 2). The "Study" group had significantly lower VAS for postoperative pain when compared to "Control" group patients.

\section{Mean Time to First Rescue Analgesia}

The mean time to first rescue analgesia in the "Control" group was $2.1 \pm 1.125$ hours and in the "Study" group it was $11.7 \pm 7.344$ hours which was statistically highly significant $(p<0.001)$ (Table 3$)$. All patients in the "Control" group required first rescue analgesia within the first 6 hours of CD. Whereas, only $18 \%(n=9)$ of patients in the "Study" group required rescue analgesia within the first 6 hours. Eighteen percent $(n=9)$ of patients in the "Study" group, who had received surgical TAP block, did not require any postoperative rescue analgesia in the first 24 hours (Table 4).

Table 1: Demographic profile of two groups

\begin{tabular}{lcrl}
\hline & $\begin{array}{c}\text { Control }(n=50) \\
(\text { Mean } \pm S D)\end{array}$ & $\begin{array}{l}\text { Study }(n=50) \\
\text { (Mean } \pm S D)\end{array}$ & $\begin{array}{l}p \text { value* (Student's } \\
\text { " } t \text { " test })\end{array}$ \\
\hline Age (years) & $24.02 \pm 3.437$ & $24.98 \pm 3.889$ & 0.19 \\
Height $(\mathrm{cm})$ & $162.80 \pm 2.814$ & $161.62 \pm 3.206$ & 0.053 \\
Weight $(\mathrm{kg})$ & $73.46 \pm 4.577$ & $73.50 \pm 4.510$ & 0.96 \\
\hline * $p$ value $<0.05$ is considered significant
\end{tabular}

Table 2: VAS for postoperative pain in the two groups

\begin{tabular}{lccc}
\hline VAS score & $\begin{array}{l}\text { Control }(n=50) \\
(\text { Mean } \pm S D)\end{array}$ & $\begin{array}{l}\text { Study }(n=50) \\
(\text { Mean } \pm S D)\end{array}$ & $\begin{array}{l}\text { pvalue* } \text { (Stu- } \\
\text { dent's " } t \text { " test })\end{array}$ \\
\hline 60 minutes & $2.62 \pm 1.048$ & $1.34 \pm 0.587$ & $<0.001$ \\
2 hours & $3.06 \pm 0.913$ & $1.66 \pm 0.745$ & $<0.001$ \\
4 hours & $2.84 \pm 0.866$ & $1.94 \pm 0.845$ & $<0.001$ \\
6 hours & $2.82 \pm 0.825$ & $2.42 \pm 0.810$ & 0.012 \\
12 hours & $2.94 \pm 0.867$ & $2.50 \pm 0.763$ & 0.008 \\
24 hours & $2.20 \pm 0.495$ & $2.00 \pm 0.452$ & 0.037 \\
\hline
\end{tabular}

${ }^{*} p$ value $<0.05$ is significant

\section{Total Tramadol Requirement}

The mean of total tramadol consumed in the "Study" group was 50 $\pm 28.571 \mathrm{mg}$, whereas, in the "Control" group, it was $180 \pm 26.726$ $\mathrm{mg}$. This difference was statistically highly significant (Table 3 ).

\section{Patient Satisfaction Scores}

Satisfaction scores were recorded for only 80 patients, 40 from the "Study" group and 40 from the "Control" group. Satisfaction scores were not a part of the initial pilot study of 20 patients. This score was incorporated in the main study, after a review of the pilot study data. The patients were asked to record the "Satisfaction" score after 24 hours of CD. There was a significant difference in the satisfaction scores between the two groups, with patients in the "Study" group recording higher satisfaction with their postoperative analgesia (Table 5).

\section{Ease of Performance}

In our study, surgical TAP block was performed by staff with varying levels of experience, i.e., Professors (P), Assistant Professors (AP), and also Postgraduates (PG) students under supervision. Results show that TAP blocks were performed with a similar success rate when administered by an experienced obstetrician or a junior doctor, as there was no significant difference in the time duration for the requirement of first rescue analgesia. There were no complications of TAP block encountered in the study. This indirectly points to the ease of performing the surgical TAP block, i.e., an experienced obstetrician or a junior doctor could perform the surgical TAP block with equal ease and achieve a similar success rate (Table 6).

Table 3: Observations

\begin{tabular}{llll}
\hline & $\begin{array}{l}\text { Control }(n=50) \\
(\text { Mean } \pm S D)\end{array}$ & $\begin{array}{l}\text { Study }(n=50) \\
(\text { Mean } \pm S D)\end{array}$ & $\begin{array}{l}p \text { value* }(\text { Stu- } \\
\text { dent's "t" test })\end{array}$ \\
\hline $\begin{array}{l}\text { Time for first } \\
\text { demand } \\
\text { of rescue } \\
\text { analgesic in }\end{array}$ & $2.1 \pm 1.125$ & $11.7 \pm 7.344$ & $\begin{array}{l}t=84.182, p< \\
0.001\end{array}$ \\
$\begin{array}{l}\text { hours } \\
\begin{array}{l}\text { Total analgesic } \\
\text { dose required }\end{array}\end{array}$ & & \\
in first 24 hours & & & \\
\hline * $p$ value $<0.05$ is significant & $52 \pm 28.571$ & $t=552.067, p$ \\
\end{tabular}

Table 4: Time of first rescue analgesia

\begin{tabular}{lclc}
\hline Time & Control & Study & Total \\
\hline$<6$ hours & 50 & 09 & 59 \\
$6-11$ hours & 0 & 17 & 17 \\
$12-17$ hours & 0 & 12 & 12 \\
$18-24$ hours & 0 & 12 & $12^{*}$ \\
Total & 50 & 50 & 100
\end{tabular}

*Nine patients did not require any rescue analgesia for 24 hours

Table 5: Patient satisfaction scores

\begin{tabular}{llllllll}
\hline $\begin{array}{l}\text { Satisfaction } \\
\text { score }\end{array}$ & $N$ & Minimum & Maximum & Mean & Std. deviation & t value & $p$ value \\
\hline Control & 40 & 6 & 7 & 6.72 & 0.452 & 331.5 & $<0.001$ \\
Study & 40 & 7 & 9 & 7.57 & 0.594 & & \\
\hline
\end{tabular}

${ }^{*} p$ value $<0.05$ is significant 
Surgical Transversus Abdominis Plane Block

Table 6: Ease of performance

\begin{tabular}{lllllll}
\hline & \multicolumn{5}{c}{ Time of first rescue analgesia } \\
\cline { 3 - 6 } Doctor $^{*}$ & $N$ & Minimum & Maximum & Mean & Std. deviation & Fvalue \\
\hline P & 11 & 3 & 24 & 14.82 & 7.278 & 1.417 \\
AP & 17 & 1 & 24 & 11.94 & 7.750 & 0.25 \\
PG & 22 & 2 & 24 & 10.27 & 6.991 & \\
Total & 50 & 1 & 24 & 11.84 & 7.380 & \\
\hline
\end{tabular}

*Professor (P), Assistant Professor (AP), Postgraduate (PG) Student

\section{Discussion}

The casual attitude of women toward $C D$ is pushing up the overall $C D$ rates to as high as $63 \%$, and in higher socioeconomic classes the $\mathrm{CD}$ rates are as high as $70.5 \%{ }^{10} \mathrm{Good}$ postoperative pain relief is of critical importance for every woman undergoing CD. Inadequate pain management in the immediate postoperative period is associated with a longer recovery period and delay in discharge from the hospital. High pain scores have been associated with delayed mobilization and act as a barrier to the mother's ability to be independent, to look after her newborn baby. Multimodal analgesia is a key component in the management of postoperative pain following $C D$. There are several options for effective postoperative pain control, and the choice is partly determined by individual doctor's preferences and availability.

\section{Postoperative Analgesia}

The difference in mean VAS at the predetermined time intervals between the two groups was significant $(p<0.05)$. This supports our principal finding that the technique of surgical TAP block with $20 \mathrm{~mL}$ of $0.25 \%$ bupivacaine, instilled on either side, during the operative procedure (before the closure of abdominal incision), is effective in providing significant postoperative analgesia, for the first 24 hours in patients undergoing CD.

Owen et al. first described the surgical technique of TAP block in 2010, performed during CD. They reported that categorical pain scores after 6-9 hours of surgery, were significantly lower in women after surgical TAP blocks, similar to the findings of our study. ${ }^{9}$ Similar finding were also reported by McDonnell et al. who used transcutaneous TAP block after CD, and Carney et al. who performed TAP blocks after open appendectomy and total abdominal hysterectomy. ${ }^{4,11,12}$

However, the beneficial effects of the TAP block have not been consistent. Few studies including a meta-analysis and a review of the Cochrane database showed that TAP block did not improve the postoperative pain scores. ${ }^{13-15}$

\section{Rescue Analgesia}

\section{Time to First Rescue Analgesia}

The mean time to request for first rescue analgesia in the "Control" group was 2.14 hours and in the "Study" group it was 11.78 hours, this difference was statistically highly significant. The number of participants who required rescue analgesia within the first 6 hours in the "Control" group was 100\% $(n=50)$; however, in the "Study" group, only $18 \%(n=9)$ needed rescue analgesia within the first 6 hours. More interestingly, 24\% $(n=12)$ of participants from the "Study" group did not need any rescue analgesia in the first 24 hours. This may be the effect of inherently poorly vascularized transversus abdominal plane which results in slower drug clearance. $^{12}$
Inadequate analgesia as demonstrated by the early requirement of rescue analgesia, despite administration of surgical TAP block was seen in a few cases. This may be either due to faulty technique, i.e., the needle tip was not in the correct plane, or due to the visceral pain component which is not addressed by the TAP block. The success of all regional block techniques is highly operator dependent, and studies have reported a failure rate of $5-20 \%$ for TAP blocks as well. ${ }^{16}$

\section{Total Tramadol Requirement}

In our study, the surgical TAP block was associated with a significant reduction in the total tramadol consumption in the postoperative period. The total consumption of inj. tramadol in the "Control" group was 9,050 mg for 50 patients, amounting to an average of $181 \mathrm{mg}$ per patient in the first 24 hours. For the "Study" group, the total figure was $2,600 \mathrm{mg}$ with an average of only $52 \mathrm{mg}$ per patient in the first 24 hours after surgery. This was a statistically highly significant reduction in the total amount of rescue analgesic consumption in the "Study" group, which had received surgical TAP block.

In 2010, Owen et al. reported a significant reduction in postoperative opioid requirement with surgical TAP block given during CD. ${ }^{9}$ Similar findings have also been reported by Brady et al., Srivastava et al., and Kahsay et al. ${ }^{17-19}$ Opioid use often leads to postoperative nausea, vomiting, and respiratory depression. Tramadol is a synthetic opioid analgesic that is better tolerated and provides effective postoperative analgesia comparable to most other opioid derivatives.

\section{Ease of Performance and Safety of Surgical Transversus Abdominis Plane Block}

A surgical approach to the TAP block is a quick and easy means of establishing a reliable block to provide good analgesia. The initial few cases were performed by senior obstetricians with $>15$ years of experience. Thereafter, the surgical TAP blocks were performed under supervision by all staff and postgraduate students in the department.

In obese individuals, the surgical TAP block can be easily accomplished, whereas, other modalities of giving TAP block to obese individuals are considerably more challenging. This intraoperative and intra-abdominal approach ensures asepsis is achieved. Correct placement of the needle under vision ensures the safety and avoids injury to inferior epigastric vessels and the gut. ${ }^{9}$ The theoretical risk of intravascular injection of the local anesthetic persists, but the risk can be reduced by taking simple precautions like withdrawing the plunger before injecting the anesthetic drug, to ensure that the tip of the needle is not in a blood vessel. No complications were encountered during the surgical TAP block procedure in our study; however, the surgeon should be aware of the common cardiovascular and neurological side effects like 
hypotension, bradycardia, arrhythmia, paresthesia, especially circumoral and convulsions.

\section{Patient Satisfaction}

The patients were asked to score their satisfaction with the postoperative analgesia that they received after CD. Satisfaction scores were marked on a scale of 0 to 10 and were recorded 24 hours after CD. All patients in the "Study" group had significantly better satisfaction scores when compared to the patients in the "Control" group.

Our study results have demonstrated that surgical TAP block is an important tool in the armamentarium of an obstetrician, to overcome postoperative pain. It is highly effective and easy to perform and it is hoped that it will be used more often to ease the pain of patients undergoing $C D$.

\section{CONCLUSION}

Surgical TAP block is a relatively new technique of performing a wellestablished regional block for postoperative pain management. The technique is easy to perform and can be easily mastered by any obstetrician. It provides effective and prolonged postoperative analgesia and a significant reduction in the amount of postoperative rescue analgesic use. Surgical TAP block is an important adjunct in the multimodal pain management strategy that can significantly improve the patient satisfaction scores for patients undergoing $C D$.

\section{Clinical Significance}

The surgical TAP block is an established technique for postoperative analgesia following abdominal surgery. However, it has not been practiced frequently by obstetricians. The greatest strength of our study was that this study provided an opportunity for our staff and postgraduate students to learn a new skill. It was performed with equal ease and efficacy by senior and junior obstetricians and postgraduate students. The results have boosted the confidence in this simple technique of surgical TAP block, and we hope more and more obstetricians will be encouraged to use surgical TAP block in their practice. The fairly large sample size further boosted our confidence in the safety and the ease of performance of this technique.

The limitation of our study was that we did not record the different surgical steps during CD for each patient. For example, if the surgeon encountered adhesions or advancement of the bladder in repeat $C D$, if the obstetrician closed the parietal peritoneum or not during $C D,{ }^{20}$ etc. These parameters could potentially influence the total dose of rescue analgesia as well as the timing of the first rescue analgesia required.

\section{References}

1. Netter FH. Back and spinal cord. In: Netter FH, ed. Atlas of Human Anatomy. Summit, New Jersey: The Ciba-Geigy Corporation; 1989. pp. $145-155$.

2. Netter FH. Abdomen postero lateral abdominal wall. In: Netter FH, ed. Atlas of Human Anatomy. Summit, New Jersey: The Ciba-Geigy Corporation; 1989. pp. 230-240.

3. Rafi A. Abdominal field block: a new approach via the lumbar triangle. Anaesthesia 2001;56(10):1024-1026. DOI: 10.1046/j.13652044.2001.02279-40.x.
4. McDonnell JG, O'Donnell B, Curley G, et al. The analgesic efficacy of transverses abdominis plane block after abdominal surgery: a prospective randomized controlled trial. Anesth Analg 2007;104(1):193-197. DOI: 10.1213/01.ane.0000250223.49963.0f.

5. McDonnell JG, Curley G, Carney J, et al. The analgesic efficacy of transversus abdominis block after caesarean delivery. Anaesth Analg 2008;106(1):186-191. DOI: 10.1213/01.ane.0000290294.64090.f3.

6. French JLH, McCullough J, Bachra P, et al. Transversus abdominis plane block for analgesia after caesarean section in a patient with an intracranial lesion. Int J Obstet Anesthe 2009;18(1):52-54. DOI: 10.1016/j.ijoa.2008.06.005.

7. Randall IM, Costello J, Carvalho JC. Transversus abdominis plane block in a patient with debilitating pain from an abdominal wall hematoma following cesarean delivery. Anesth Analg 2008;106(6):1928. DOI: 10.1213/ane.0b013e318170baf3.

8. Belavy D, Cowlishaw PJ, Howes M, et al. Ultrasound-guided transversus abdominis plane block for analgesia after caesarean delivery. Br J Anaesth 2009;103(5):726-730. DOI: 10.1093/bja/aep235.

9. Owen DJ, Harrod I, Ford J, et al. The surgical transversus abdominis plane block-a novel approach for performing an established technique. Br J Obstet Gynaecol 2011;118(1):24-27. DOI: 10.1111/j.14710528.2010.02779.x.

10. Alaa-El-Din Wali A, Taher A, Abd-El-Fatah SM. Awareness, knowledge, and attitude of Egyptian women toward cesarean delivery: a crosssectional survey. J South Asian Feder Obst Gynae 2020;12(4):203-208. DOI: $10.5005 /$ jp-journals-10006-1768.

11. Carney J, Finnerty O, Rauf J, et al. Ipsilateral transversus abdominis plane block provides effective analgesia after appendectomy in children: a randomized controlled trial. Anesth Analg 2010;111:9981003. DOI: 10.1213/ANE.0b013e3181ee7bba.

12. Carney J, McDonnell JG, Ochana A, et al. The transversus abdominis plane block provides effective postoperative analgesia in patients undergoing total abdominal hysterectomy. Anesth Analg 2008;107(6):2056-2060. DOI: 10.1213/ane.0b013e3181871313.

13. Petersen PL, Mathiesen O, Stjernholm P, et al. The effect of transversus abdominis plane block or local anaesthetic infiltration in inguinal hernia repair: a randomised clinical trial. Eur J Anaesthesiol 2013;30(7):415-421. DOI: 10.1097/EJA.0b013e32835fc86f.

14. Charlton S, Cyna AM, Middleton P, et al. Perioperative transversus abdominis plane (TAP) blocks for analgesia after abdominal surgery. Cochrane Database Syst Rev 2010;8:CD007705.

15. Johns N, O'Neill S, Ventham NT, et al. Clinical effectiveness of transversus abdominis plane (TAP) block in abdominal surgery: a systematic review and meta-analysis. Colorectal Dis 2012;14(10):e635e642. DOI: 10.1111/j.1463-1318.2012.03104.x.

16. Galante D, Caruselli M, Dones F, et al. Ultrasound guided transversus abdominis plane (TAP) block in pediatric patients: not only a regional anesthesia technique for adults. Anaesth Pain Intensive Care 2012;16:201-204.

17. Brady RR, Ventham NT, Roberts DM, et al. Open transversus abdominis plane block and analgesic requirements in patients following right hemicolectomy. Ann R Coll Surg Engl 2012;94(5):327-330. DOI: 10.13 08/003588412X13171221589856.

18. Srivastava U, Verma S, Singh TK, et al. Efficacy of trans abdominis plane block for post cesarean delivery analgesia: a doubleblind, randomized trial. Saudi J Anaesth 2015;9(3):298-302. DOI: 10.4103/1658-354X.154732.

19. Kahsay DT, Elsholz W, Bahta HZ. Transversus abdominis plane block after caesarean section in an area with limited resources. South Afr J Anaesthe Analge 2017;23(4):90-95. DOI: 10.1080/22201181.2017.1349361.

20. Poddar S, Tripathy S. Double-blind randomized controlled trial comparing the effect of closure vs nonclosure of peritoneum during cesarean section on postoperative pain. J South Asian Feder Obst Gynae 2019;11(3):167-171. DOI: 10.5005/jp-journals-10006-1691. 